\title{
Meiotic behaviour of two human reciprocal translocations
}

\author{
J EGOZCUE, S MARINA, AND C TEMPLADO
}

From the Department of Cell Biology, Faculty of Science; the Department of Biology, Faculty of Medicine; the Instituto de Biología Fundamental; and the Fundación Puigvert, Universidad Autónoma de Barcelona, Barcelona, Spain.

SUMmaRY The meiotic behaviour of two male human reciprocal translocations is described. One patient had an unbalanced son and a chain configuration. The second had a stillborn child and a ring corresponding to an adjacent I segregation. The meiotic behaviour of chromosomal rearrangements must be investigated for proper genetic counselling.

According to the data of Jacobs et al ${ }^{1}$ the incidence of balanced chromosomal rearrangements in the adult population is $3 \cdot 32$ per 1000 . The most common type is the translocation. In newborns ${ }^{2}$ the incidence of balanced reciprocal translocations is less than 1 in 1000, but in subfertility clinics the incidence is much higher. In our series of 1015 subfertile males (up to 31 May 1980) in whom mitotic or meiotic studies or both have been carried out, we have found five reciprocal translocations. In spite of the prognostic importance of the meiotic behaviour of the translocation products, to our knowledge only ten cases have been published. ${ }^{3-8}$

In this paper we describe the meiotic findings in two subfertile males, heterozygous for reciprocal translocations.

Received for publication 30 September 1980

\section{Material and methods}

The two cases were referred for chromosome studies by the Department of Andrology, Fundación Puigvert. Peripheral blood cultures were carried out using commercial kits and analysed by $\mathrm{G}$ banding ${ }^{9}$ and $\mathrm{Q}$ banding. ${ }^{10}$ In case 1 meiosis was studied in semen using the technique of Sperling and Kaden ${ }^{11}$ as modified by us. ${ }^{12}$ In case 2 a testicular biopsy was obtained under local anaesthesia and meiotic preparations were made using the technique of Evans et al. ${ }^{13}$

\section{Results}

CASE $1.46, \mathrm{XY}, \mathrm{t}(10 ; 13)(\mathrm{q} 25 ; \mathrm{p} 12)$

This patient, aged 34 , had a son with mental

FIG 1 Diakinesis and chain configurations in the carrier of a $(10 ; 13)$ translocation. 


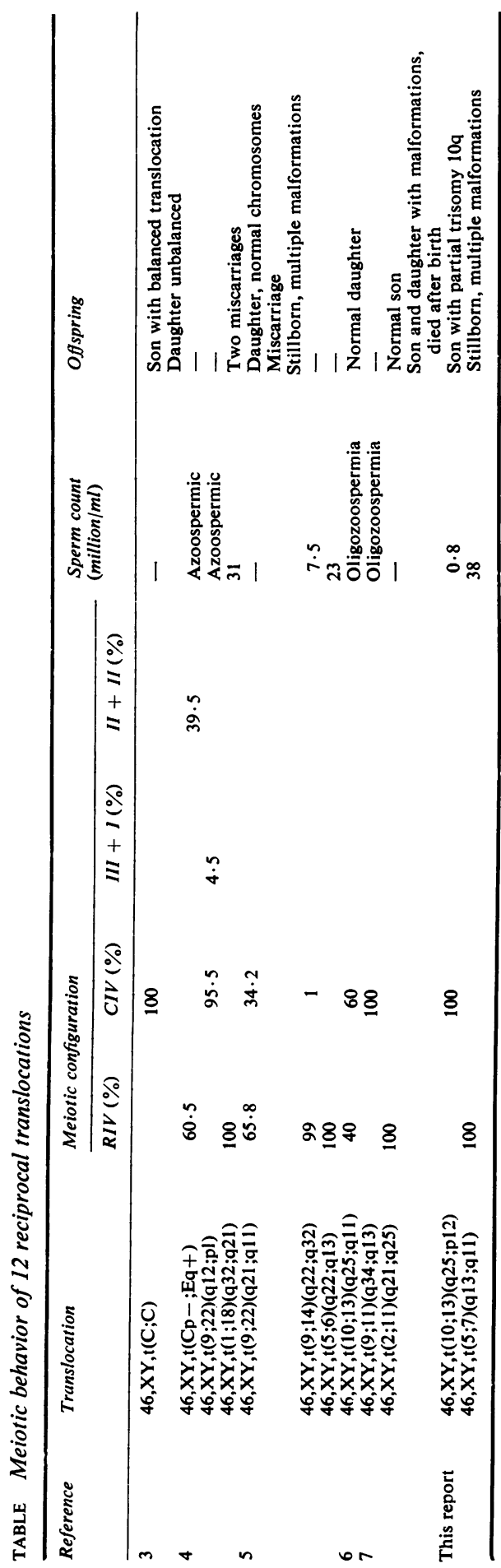

retardation. Lymphocyte metaphases showed a balanced reciprocal translocation $(10 ; 13)$. His son had a partial trisomy 10 reported by Miró et al. ${ }^{8}$

The spermiogram showed severe oligozoospermia (table). At meiosis all stages of the cycle were found. All 37 diakineses studied had a tetravalent in the form of an open chain resulting from failure of chiasma formation in one of the pairing regions of the translocation cross (fig 1).

CASE $2.46, \mathrm{XY}, \mathrm{t}(5 ; 7)(\mathrm{q} 13 ; \mathrm{q} 11)$

This patient, aged 25 , requested counselling because his wife had given birth to a malformed fetus at 8 months' gestation. Cytogenetic studies showed a balanced $(5 ; 7)$ reciprocal translocation.

The spermiogram showed oligoasthenoteratozoospermia. At meiosis, the number of divisions was low, but all 19 diakineses studied had a tetravalent with the same configuration (fig 2) resulting from chiasma formation in all four pairing regions and one interstitial region.

\section{Discussion}

The number of meiotic studies in reciprocal translocation carriers is still low (table) and none of the published articles deals in depth with the genetic counselling implications of the meiotic figures observed, although Chandley et al ${ }^{414}$ have repeatedly indicated that chain configurations carry a worse prognosis than rings, because of the fact that in such cases meiotic breakdown is more frequent.

Case 1 had a translocation involving band 10q25, which has recently been shown to be a fragile site, although it is only expressed by BrdU incorporation. ${ }^{15} 16$

In Robertsonian fusions, counsellors may give a $33 \%$ theoretical risk or a 2 to $10 \%$ empirical risk depending on whether the carrier is the male or the female. ${ }^{17}$ However, as Moses et al ${ }^{18}$ have shown in Lemur hybrids, this risk may be as low as $0 \%$ if pairing of the trivalent always takes place in the cis configuration, and higher than the theoretical $33 \%$ if pairing is in trans.

In reciprocal translocations, the theoretical risk is at least $50 \%$, because adjacent segregation is probably as frequent as alternate segregation. ${ }^{19}$ However, in most published cases $^{3-8}$ adjacent segregation has been the rule.

Finally, it must be taken into account that some types of translocation predispose to 3:1 disjunction. ${ }^{20}$ These are the translocations involving an acrocentric, particularly a short one, and those with extreme disparity in total chromosome length. The behaviour of human reciprocal translocations has recently been reviewed by Jalbert $e t$ al. ${ }^{21}$ 


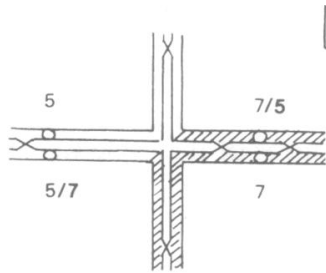

$t(5 ; 7)(q 13 ; q 11)$

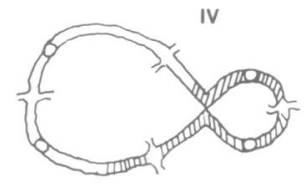

FIG 2 Diakineses and ring configurations in the carrier of $a(5 ; 7)$ translocation. Note terminal chiasmata close to interstitial chiasma (arrows).
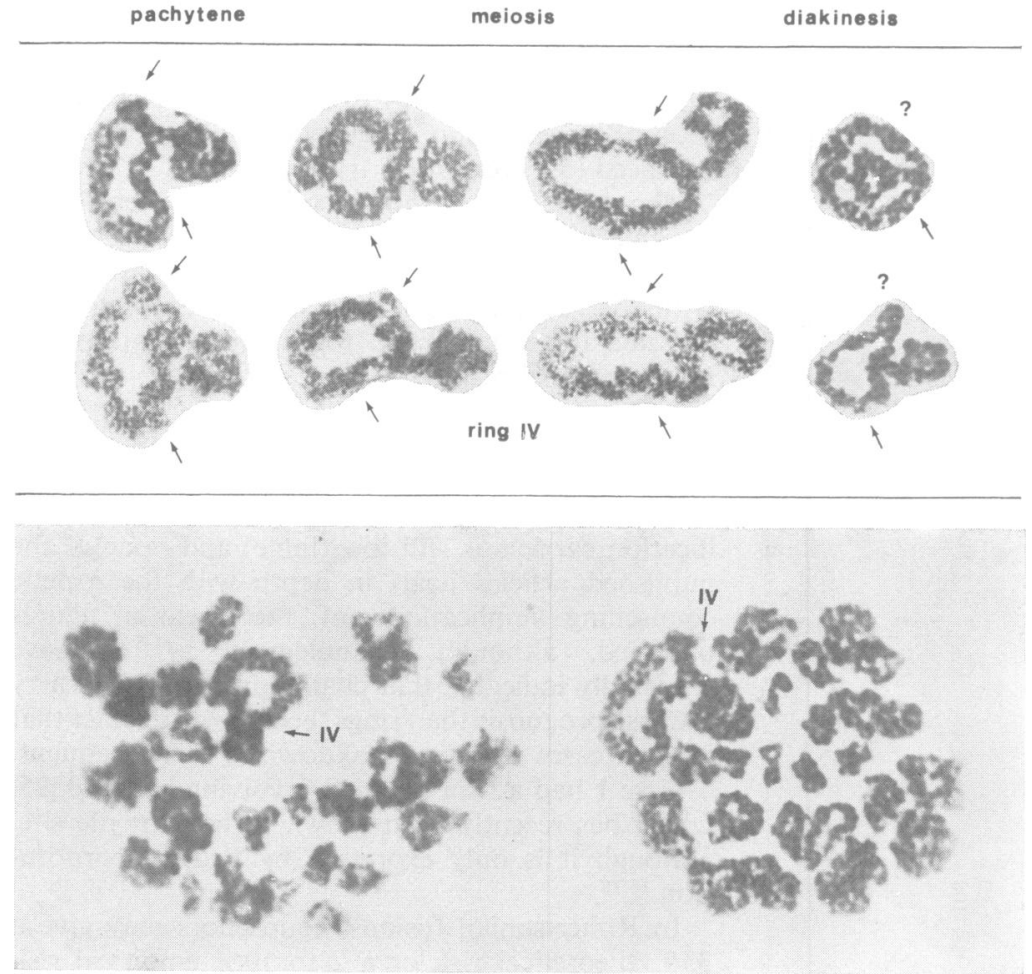

Thus, the study of the meiotic behaviour of translocated chromosomes and of their pairing characteristics should be considered essential for counselling translocation carriers. Although it is not always easy to obtain gonadal material, ${ }^{512}$ the possibility of carrying out meiotic ${ }^{12}$ and synaptonemal complex studies in the ejaculate ${ }^{22}$ enables investigations in all male carriers to be carried out.

We thank Dr A Fortuny, Department of Obstetrics and Gynecology, Hospital Clínico y Provincial de Barcelona, who karyotyped patient 2.

\section{References}

I Jacobs PA, Frackiewicz A, Law P. Incidence and mutation rates of structural rearrangements of the autosomes in man. Ann Hum Genet 1972;35:301-19.
2 Evans JA, Canning N, Hunter AGW, et al. A cytogenetic survey of 14,069 newborn infants. III. An analysiso of the significance and cytologic behavior of the Robertsonian and reciprocal translocations. Cytogenet Cell Genet 1978;20:96-123.

Lindsten J, Fraccaro M, 7 Klinger HP, Zetterqvist P. Meiotic and mitotic studies of a familial reciprocar translocation between two autosomes of group 6-12. N Cytogenetics $1965 ; 4: 45-64$.

4 Chandley AC, Christie S, Fletcher J, Frackiewicz A, Jacobs PA. Translocation heterozygosity and associated $<$ subfertility in man. Cytogenetics 1972;11:516-33.

5 Chandley AC, Seuánez H, Fletcher JM. Meiotic behavior胥 of five human reciprocal translocations. Cytogenet Celf Genet 1976;17:98-111.

${ }^{6}$ Laurent C, Biemont MC, Cognat M, Dutrillaux B. Studies of the meiotic behavior of a translocation $\mathrm{t}(10 ; 13)(\mathrm{q} 25 ; \mathrm{q} 11)$ in an oligospermic man. Hum Genetid $1977 ; 39: 123-6$. 
7 San Román C, Sordo MT, García-Sagredo JM. Meiosis in two human reciprocal translocations. $\mathrm{J}$ Med Genet $1979 ; 16: 56-9$.

8 Miró R, Templado C, Ponsá M, Serradell J, Marina S, Egozcue J. Balanced translocation $(10 ; 13)$ in a father, ascertained through the study of meiosis in semen, and partial trisomy $10 \mathrm{q}$ in his son. Hum Genet 1980;53: 179-82.

9 Gallimore PM, Richardson CR. An improved banding technique exemplified in the karyotype analysis of two strains of rat. Chromosoma 1973;41:259-63.

10 Polani PE, Mutton DE. Y-fluorescence of interphase nuclei, specially circulating lymphocytes. Br Med J 1971; 1:138-42.

11 Sperling K, Kaden R. Meiotic studies of the ejaculated seminal fluid of humans with normal sperm count and oligospermia. Nature 1971;232:481.

12 Templado C, Marina S, Coll MD, Egozcue J. Meiotic studies in human semen. Report of 180 cases. Hum Genet 1980: 53:335-9.

13 Evans EP, Breckon G, Ford CE. An air-drying method for meiotic preparations from mammalian testes. Cytogenetics 1964;3:289-94.

14 Chandley AC. The chromosomal basis of human infertility. Br Med Bull 1979;35:181-6.

15 Sutherland GR, Baker E, Seshadri RS. Heritable fragile sites on human chromosomes. V. A new class of fragile site requiring BrdU for expression. Am J Hum Genet
$1980 ; 32: 542-8$.

16 Scheres JMJC, Hustinx TWJ. Heritable fragile sites and lymphocyte culture medium containing BrdU. Am J Hum Genet $1980 ; 32: 628-9$.

17 Fuhrmann W, Vogel F. Chromosome aberrations. In: Genetic counseling. New York: Springer, 1976: 61-79.

18 Moses MJ, Karatsis PA, Hamilton AE. Synaptonemal complex analysis of heteromorphic trivalents in Lemur hybrids. Chromosoma 1979;70:I41-60.

19 Ford CE, Clegg HM Reciprocal translocations. $\mathrm{Br} \mathrm{Med}$ Bull 1969; 25: 110-4.

20 Lindenbaum RH, Bobrow M. Reciprocal translocations in man. 3:1 meiotic disjunction resulting in 47 - or $45-$ chromosome offspring. J Med Genet 1975;12:29-43.

21 Jalbert P, Sele B, Jalbert H. Reciprocal translocations: a way to predict the mode of imbalanced segregation by pachytene-diagram drawing. A study of 151 human translocations. Hum Genet $1980 ; 55: 209-22$.

22 Vidal F, Navarro J, Guitart M, Coll MD, Egozcue J. (1980). Estudi de complexes sinaptinèmics en microscòpia electrònica. VIII Meeting Inst Cat Hist Nat and Soc Cat Biol, Blanes, Barcelona, May 3I-June 1.

Requests for reprints to Dr J Egozcue, Instituto de Biología Fundamental, Av S Antonio M Claret 171, Barcelona, Spain. 